\title{
Infrasonic wave accompanying a crack opening during the 2015 Hakone eruption
}

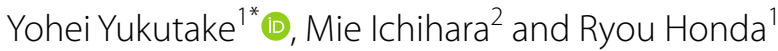

\begin{abstract}
To understand the initial process of the phreatic eruption of the Hakone volcano from June 29 to July 01, 2015, we analyzed infrasound data using the cross-correlation between infrasound and vertical ground velocity and compared the results of our analysis to the crustal deformation detected by tiltmeters and broadband seismometers. An infrasound signal and vertical ground motion due to an infrasound wave coupled to the ground were detected simultaneously with the opening of a crack source beneath the Owakudani geothermal region during the 2-min time period after 07:32 JST on June 29, 2015 (JST = UTC $+8 \mathrm{~h}$ ). Given that the upper end of the open crack was approximately $150 \mathrm{~m}$ beneath the surface, the time for the direct emission of highly pressurized fluid from the upper end of the open crack to the surface should have exceeded the duration of the inflation owing to the hydraulic diffusivity in the porous media. Therefore, the infrasound signal coincident with the opening of the crack may reflect a sudden emission of volcanic gas resulting from the rapid vaporization of pre-existing groundwater beneath Owakudani because of the transfer of the volumetric strain change from the deformation source. We also noticed a correlation pattern corresponding to discrete impulsive infrasound signals during vent formation, which occurred several hours to 2 days after the opening of the crack. In particular, we noted that the sudden emission of vapor coincided with the inflation of the shallow pressure source, whereas the eruptive burst events accompanied by the largest vent formation were delayed by approximately 2 days. Furthermore, we demonstrated that the correlation method is a useful tool in detecting small infrasound signals and provides important information regarding the initial processes of the eruption.
\end{abstract}

Keywords: Infrasound signal, Vertical ground motion, Correlation, Monitoring, Volcanic activity, Phreatic eruption

\section{Introduction}

Phreatic eruptions are generally thought to involve the transfer of magmatic or hydrothermal heat to circulating groundwater without an eruption of fresh magma (e.g., Barberi et al. 1992). These events sometimes become explosive phenomena and cause severe damage around a vent, such as in the case of the 2014 phreatic eruption of Mt. Ontake in Japan. Considering that these phenomena are usually not accompanied by remarkable magma movement, it is difficult to observe any associated precursors. Recently, several studies have successfully detected inflations of shallow pressure sources several minutes to days prior to phreatic eruptions as shortterm precursors (e.g., Aoyama and Oshima 2015; Takagi

\footnotetext{
*Correspondence: yukutake@onken.odawara.kanagawa.jp

${ }^{1}$ Hot Springs Research Institute of Kanagawa Prefectural Government,

586 Iriuda, Odawara, Kanagawa, Japan

Full list of author information is available at the end of the article
}

and Onizawa 2016; Iguchi et al. 2017). Therefore, understanding the initial processes during a phreatic eruption is essential to examine its preparatory processes as well as to mitigate volcanic hazards. Infrasound, seismic, and geodetic data observed during a small phreatic eruption of the Hakone volcano in central Japan (Fig. 1a) provide an excellent opportunity to understand the initial processes of a phreatic eruption.

Infrasound data provide useful information regarding eruptive activities of volcanoes, especially in situations in which visual information surrounding vents is unavailable. However, pressure signals obtained using a microphone are generally contaminated by wind noise. Therefore, to obtain meaningful infrasound signals associated with a volcanic source, a high-quality noise reduction system, such as multiple sensors in an array, is required (e.g., Ripepe and Marchetti 2002; Garcés et al. 2003). Recently, Ichihara et al. (2012) proposed a 
new method to distinguish infrasound signals from wind noise even in situations in which only one microphone is available using a cross-correlation analysis between the infrasound and vertical ground motion signals. This method has been applied and tested at other volcanoes (Yokoo and Ichihara 2012; Matoza and Fee 2014).

In this study, we applied the correlation method to the infrasound data collected during the 2015 eruption of the Hakone volcano where one microphone was co-located at a seismic station within approximately $520 \mathrm{~m}$ of the vents (Fig. 1b). We attempted to identify the infrasound signal associated with the eruptive activity. We discuss the relationship between the infrasound signals and the source process of an open crack that caused a rapid tilt change during the initial stage of the activity.

\section{Hakone eruption}

Volcanic activity of the Hakone volcano, e.g., an increase in volcano tectonic (VT) earthquakes, detection of crustal deformation, and activation of fumarolic gas emissions, gradually intensified at the end of April 2015. From June 29 to July 01, 2015, a phreatic eruption occurred in the Owakudani geothermal region on the northern slope of the central cone in the Hakone caldera where fumarolic activity is present. During this eruption, only 100 tons of the altered material that developed near the surface of the steaming area erupted (Nagai et al. 2015). The discharged mass was less than $1 \%$ of that discharged during the 2014 phreatic eruption of Mt. Ontake (Takarada et al. 2016). An abrupt increase in VT earthquakes was observed after 07:32 on June $29($ JST $=\mathrm{UTC}+8 \mathrm{~h})$ (Yukutake et al. 2017). Nearly simultaneously, a tilt change of up to $10 \mu \mathrm{rad}$ was observed during the $2 \mathrm{~min}$ after $07: 32$ by tiltmeters and broadband seismometers installed around the Owakudani region (Fig. 1a). This rapid tilt change was explained by assuming a shallow open crack source of approximately $5 \mathrm{~cm}$ in dilation oriented NW-SE and extending to an elevation of approximately 850 m (Honda et al. 2017). Doke et al. (2017) estimated a similar open crack source model beneath Owakudani using crustal deformation detected by Interferometric Synthetic Aperture Radar (InSAR) analysis. Ash fall was reported at approximately 12:00 on June 29 , and several vents formed from the afternoon of June 29 until the early morning of July 01 in the Owakudani region (Mannen et al. 2015). To understand the relationship between the deformation source process and this eruptive activity, it is important to examine the surface phenomena during the crack opening. However, owing to poor visibility in the Owakudani region, we could not observe detailed surface phenomena during the rapid tilt change (Additional file 1: Figure A1). The vent formation was initially identified at $16: 37$ on June 29 via visual observation (Mannen et al. 2015).

\section{Data and methods}

An infrasonic microphone (ACO, TYPE7144, 0.1$100 \mathrm{~Hz}$ ) was installed at the OWD seismic station (Fig. 1b) on May 21, 2015, by the Japan Meteorological Agency approximately $2 \mathrm{~m}$ from a velocity seismometer (Sercel, L-4C, $1 \mathrm{~Hz}$ ) installed by the Hot Springs Research Institute of the Kanagawa Prefectural Government. The signals were continuously recorded at a $100-\mathrm{Hz}$ sampling frequency for the microphone and $200 \mathrm{~Hz}$ for the seismometer. The station is at a distance of approximately $520 \mathrm{~m}$ from the vents that formed during the phreatic eruption (Fig. 1b).

We conducted a cross-correlation analysis between the microphone and the vertical ground velocity data at the OWD station using the method of Ichihara et al. (2012). According to Ben-Menahem and Singh (1981), the vertical ground velocity of an elastic surface wave excited by a horizontally incident pressure (infrasonic) wave is theoretically delayed by a quarter of a cycle relative to the pressure wave. Therefore, when the pressure wave propagates on the ground surface exciting the elastic surface wave, the correlation function between the infrasound and the vertical ground velocity has a positive peak near $\tau=1 /\left(4 f_{0}\right)$ ( $\tau$ and $f_{0}$ are the delay time of the ground velocity to the infrasound and the characteristic frequency of the pressure wave, respectively), a negative peak near $\tau=-1 /\left(4 f_{0}\right)$, and a node at $\tau=0$. We termed this pattern of the correlation function the correlation pattern. When the wind noise is incoherent between the microphone and the seismometer, the wind noise component in the recorded infrasound and seismic traces cancels out in the cross-correlation calculation. Furthermore, the infrasound noise because of the incidence of a seismic wave is also canceled out by the correlation analysis in most cases because the pressure change caused by an incident seismic wave does not have significant power (Ichihara et al. 2012). Therefore, we can effectively identify the infrasonic signal as the correlation pattern.

Prior to the correlation analysis, the sensitivity and characteristics of the microphone installed at the OWD station were compared to the records obtained by a well-calibrated reference microphone (Hakusan, SI104, 0.3-1500 Hz) at the same position on March 22, 2017. Impulsive calibration signals were provided to both sensors (Additional file 2: Figure A2a). As a result, we obtained the response function of the OWD microphone with respect to the reference sensor, which showed a reduction in the sensitivity and a phase shift of the OWD microphone in the frequency range used in this analysis (Additional file 2: Figures A2b and A2c). Thereafter, 


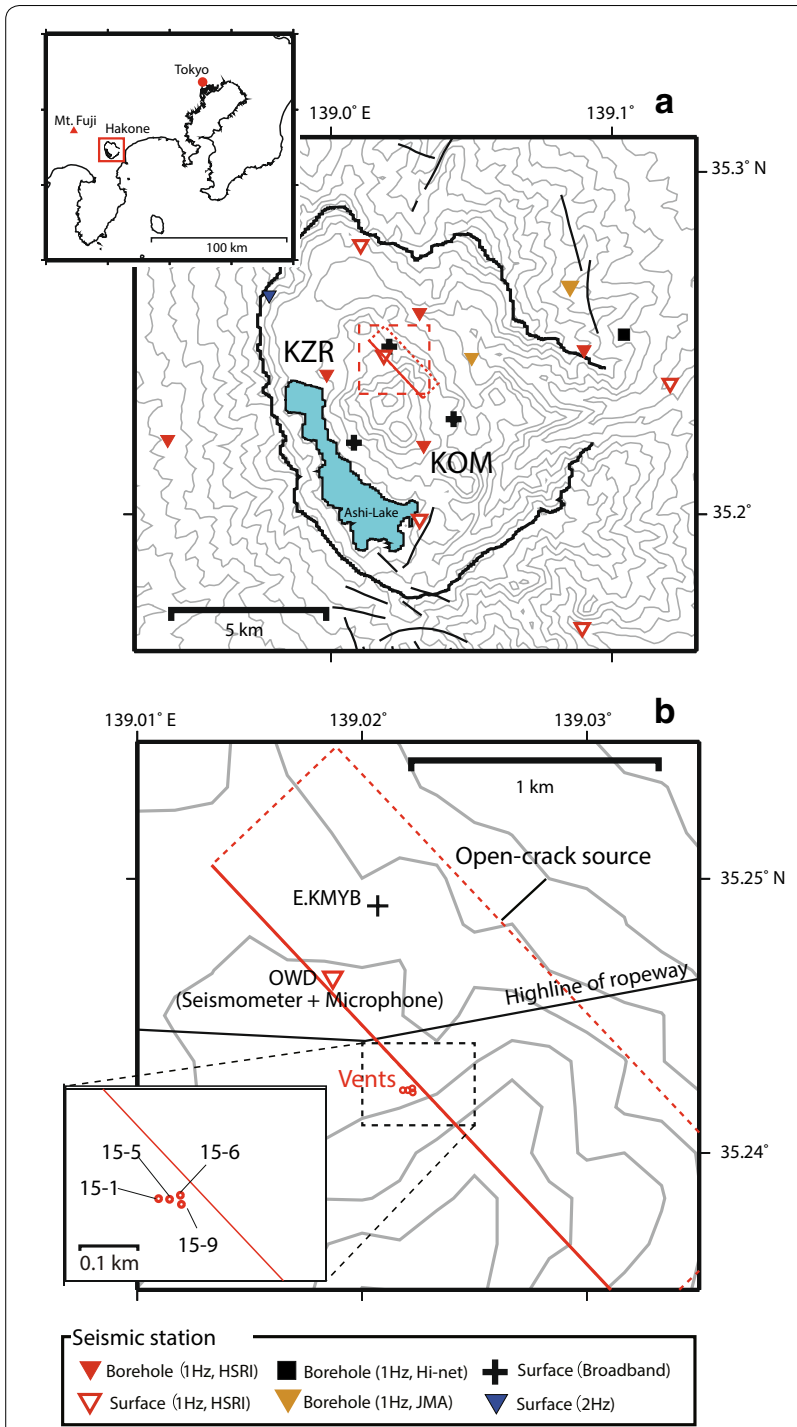

Fig. 1 Map of Hakone volcano. a Distribution of stations in and around the caldera of the Hakone volcano. The study region is indicated by the red rectangle in the inset map. The bold line shows the caldera rim of the Hakone volcano. Gray lines indicate the detailed topography of the Hakone volcano. The red broken rectangle represents the location of the open crack as determined by Honda et al. (2017). b Magnified maps of the Owakudani geothermal region. The red circles depict the locations of the vents that formed during the phreatic eruption (Mannen et al. 2015). The numbers in the inset map indicate the index numbers of the vents defined in Mannen et al. (2015)

we deconvolved the response function from the real infrasound records at the OWD station. The frequency response of the seismometer provided in the catalog was also removed from the seismic records, and the seismic records were decimated to $100 \mathrm{~Hz}$.

We investigated the signals within two frequency ranges, namely $3-12 \mathrm{~Hz}$ as the low-frequency range and $6-20 \mathrm{~Hz}$ as the high-frequency range, by applying band-pass filters to the infrasound and seismic records. Given the small distance between the microphone and the seismometer at the OWD station, frequency ranges higher than those proposed by Ichihara et al. (2012) were used in this study. The phase shift due to the inter-sensor propagation time (Matoza and Fee 2014) was negligible. A cross-correlation function of the filtered records was calculated using a 5-s sliding window within a range of $\tau$ from -0.4 to $0.4 \mathrm{~s}$. The cross-correlation function was plotted on the time $(t)$-delay $(\tau)$ axis to identify the correlation pattern associated with the infrasound signal. Furthermore, when the cross-correlation functions were plotted over a long time range $(4 \mathrm{~h})$, we stacked the correlation functions within a 20 -s time window.

\section{Results}

An example of a temporal sequence of root-mean-square (RMS) amplitudes and microphone-seismometer correlation functions in the low-frequency range from 7:00 to 11:00 on June 29, 2015, is shown in Fig. 2a, b. The correlation pattern emerges nearly simultaneously as that of the rapid tilt change and appears continuously during the first 15 min following the onset of the tilt change (Figs. 2b and 3e). An example of a temporal sequence of microphone-seismometer correlation functions in the high-frequency range from 02:30 to $06: 30$ on July 01 , 2015, is indicated in Fig. 2c, d. The correlation pattern can be identified during the period from 04:05 to 06:00. Yukutake et al. (2017) reported that the largest amplitude volcanic tremor during the eruptive activity occurred during this time period and was accompanied by discrete impulsive infrasound signals. According to Mannen et al. (2015), the largest vent 15-1 (Fig. 1b) was formed during this tremor and infrasound activity.

To confirm whether a similar correlation pattern emerged during other periods, we investigated the correlation between the reference correlation pattern and the microphone-seismometer correlation function at each time. The reference patterns were estimated from the ensemble average of the microphone-seismometer correlation functions during the period from 07:32:50 to $07: 43: 00$ on June 29 for the low-frequency range and from 04:30:00 to 05:30:00 on July 01 for the high-frequency range. The cross-correlation coefficient between the reference and each microphone-seismometer correlation function was computed from May 21, 2015, to September 30, 2016. The correlation pattern was distinguished on the basis of two conditions: (1) the cross-correlation coefficient was greater than or equal to 0.8 , and (2) the cross-correlation coefficients that satisfy the first condition last more than $2 \mathrm{~min}$. The second condition was given to avoid a coincidental match to the reference 
pattern. The correlation pattern was identified during the periods of 07:32-07:45 on June 29 and 06:57-06:59 and 10:32-10:34 on June 30 in the low-frequency range and during the period of 04:05-06:00 on July 01 in the highfrequency range (Fig. 2f).

The microphone-seismometer correlation function observed after 07:32 on June 29 was compared to the time series of the tilt changes using the seismic and microphone data as shown in Fig. 3. The increase in seismic amplitude was initially observed at 07:32:30 on June 29 (the yellow line in Fig. 3). After $20 \mathrm{~s}$, the amplitude of the infrasound signal increased, and the correlation pattern between the infrasound and the vertical ground velocity emerged (the black line in Fig. 3). The rapid tilt change was initiated nearly simultaneously as the emergence of the correlation pattern.

\section{Discussion}

Because the correlation pattern was identified only during the eruption (Fig. 2e), it was thought to reflect the occurrence of an infrasound signal associated with the eruptive activity. A slight shift of the node in the correlation pattern from the theoretical position of $\tau=0$ was observed as seen in Fig. 2d. Yokoo and Ichihara (2012) indicated that the node in the correlation pattern could be shifted from the theoretical position when a seismic single in the same frequency range as that of an infrasound signal overlapped in a ground velocity record (Additional file 3). This shift of the node may be an effect of the volcanic tremor signal observed during this period (Yukutake et al. 2017). The correlation coefficients as shown in Fig. 2b, $\mathrm{d}$ range from approximately -0.2 to 0.2 , which is low compared to examples from other volcanoes (e.g., Ichihara et al. 2012; Matoza and Fee 2014). Ichihara et al. (2012) demonstrated that during a subplinian eruption, the correlation pattern becomes less clear even if the infrasonic amplitude is very large. This is a result of the strong seismic waves that are not coupled to the infrasonic signals. The low correlation coefficients at Hakone may be explained by contamination from relatively highamplitude seismic signals generated by VT earthquakes or the volcanic tremor.

During the first $30 \mathrm{~s}$ after the onset of the rapid tilt change, the tilt record represents a reverse polarity with respect to that expected from the crack opening, i.e., a tilt downward in the NE direction at the KZR station (Fig. 3d). Thereafter, the polarity aligned with the crack opening, i.e., a tilt downward in the SW direction at the KZR station. Honda et al. (2017) demonstrated that the tilt change showing reverse polarity in the initial phase was caused by an apparent transient response of the tiltmeter, as described in Kokubo (2013), rather than a real contraction of the source. Therefore, it is suggested that the opening of the crack started simultaneously with the emergence of the correlation pattern.

The relationship between the correlation pattern and the tilt changes (Fig. 3) shows that the surface phenomena, such as rapid emission of volcanic gas, occurred concurrently with the crack opening beneath the Owakudani region even though we cannot estimate the exact scale of the upwelling. The result also suggests that the increase in the infrasound amplitude was not caused by an incidence of seismic waves. The upper end of the open crack estimated by Honda et al. (2017) is approximately $150 \mathrm{~m}$ beneath the surface of the Owakudani region, which is approximately $1000 \mathrm{~m}$ above sea level. Honda et al. (2017) indicated that the residual becomes three times larger than that of the best model when the upper end of the open crack is fixed at a depth of $50 \mathrm{~m}$ below the surface. The open crack model estimated by the ground deformations based on InSAR data (Doke et al. 2017) has an upper end at a similar elevation of $830 \mathrm{~m}$ above sea level. Because the surface area above the open crack is mostly covered with dense vegetation, it is difficult to detect subtle surface displacements via field survey. However, field surveys at Owakudani, which is a barren area because of the fumarolic activity, and along trekking courses, where the soil is exposed, did not observe any surface displacement to indicate the emergence of the open crack at the surface (Mannen, personal communication). Therefore, it is reasonable to believe that the opening of the crack did not reach the ground surface but stopped approximately $150 \mathrm{~m}$ below the surface. If we assume that the sudden opening of the crack reflects an intrusion of highly pressurized hydrothermal fluid, the instantaneous response of the infrasound signal to the rapid tilt change cannot be explained by the diffusion of the pressurized fluid from the open crack. The diffusion of the fluid from the upper end of the crack to the surface (approximately $150 \mathrm{~m}$ ) takes a longer time given the hydraulic diffusivity of the porous media of $0.5-1.0 \mathrm{~m}^{2} / \mathrm{s}$, which was estimated on the basis of the hypocenter migration of the earthquake swarms in the Hakone volcano and corresponds to a migration velocity of several tens of meters per hour (Yukutake et al. 2011). The delay in the fluid diffusion or the following heat transfer from the open crack may correspond to the timing of vent formation (Mannen et al. 2015) and the increase in the volcanic tremor amplitude (Yukutake et al. 2017) that occurred several hours after the onset of the rapid tilt change.

We then considered the relation of the strain transfer caused by the crack opening to the instantaneous response of the infrasound signal. The strain change due to the crack opening propagates to the surface nearly instantaneously in contrast to the diffusion of the fluid because the crack is very near the surface. Figure 4 shows 

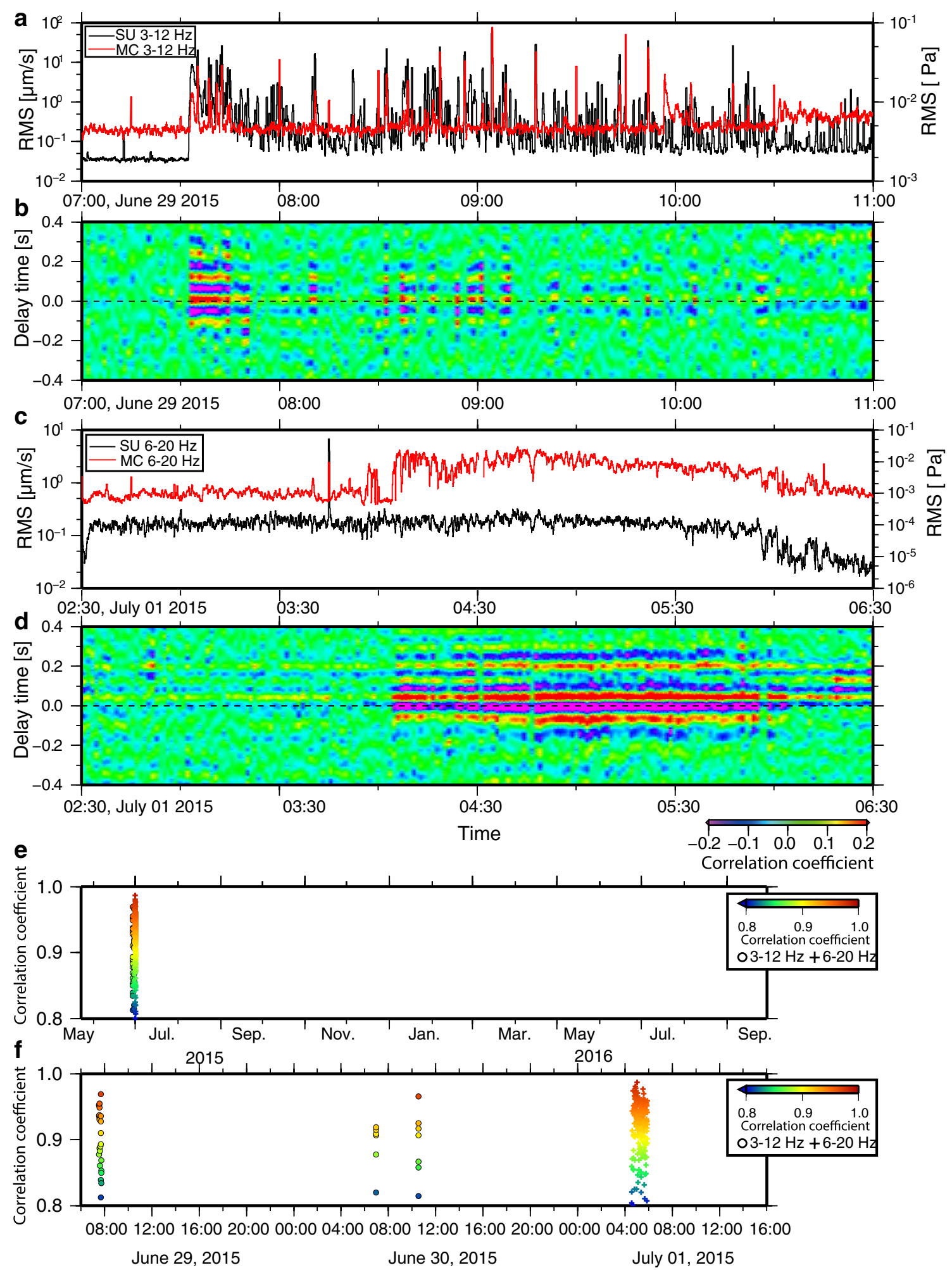

Fig. 2 Results of the cross-correlation method. a RMS amplitude over 1 min for the microphone (red line) and the vertical ground velocity (black line) at the OWD station during the period from 07:00 to 11:00 June 29, 2015 and $\mathbf{b}$ a temporal sequence of the microphone-seismometer correlation function of the band-passed seismic and infrasonic signals. c RMS amplitude during the period from 02:30 to 06:30 on July 01 and $\mathbf{d}$ a temporal sequence of the cross-correlation function. e Temporal sequence of the correlation coefficient between the reference and the microphone-seismometer correlation functions during the period from May 21, 2015, to September 30, 2016, and $\mathbf{f}$ its magnified plot during the eruption 

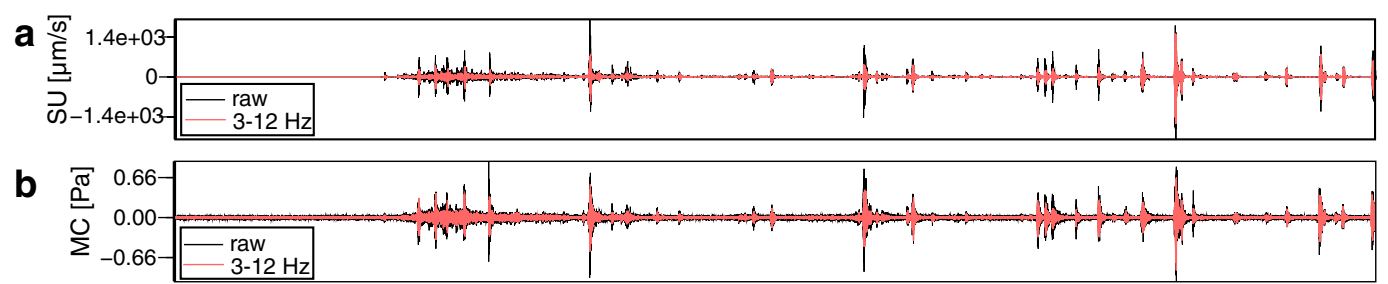

C
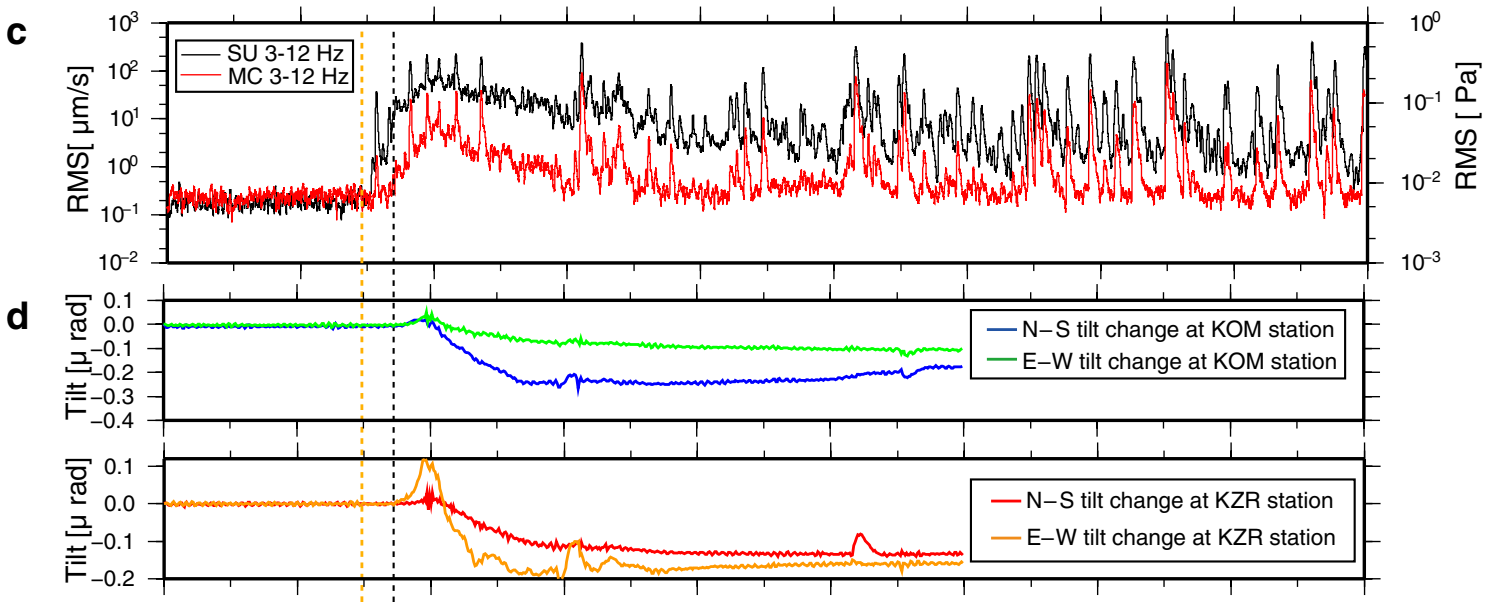

e

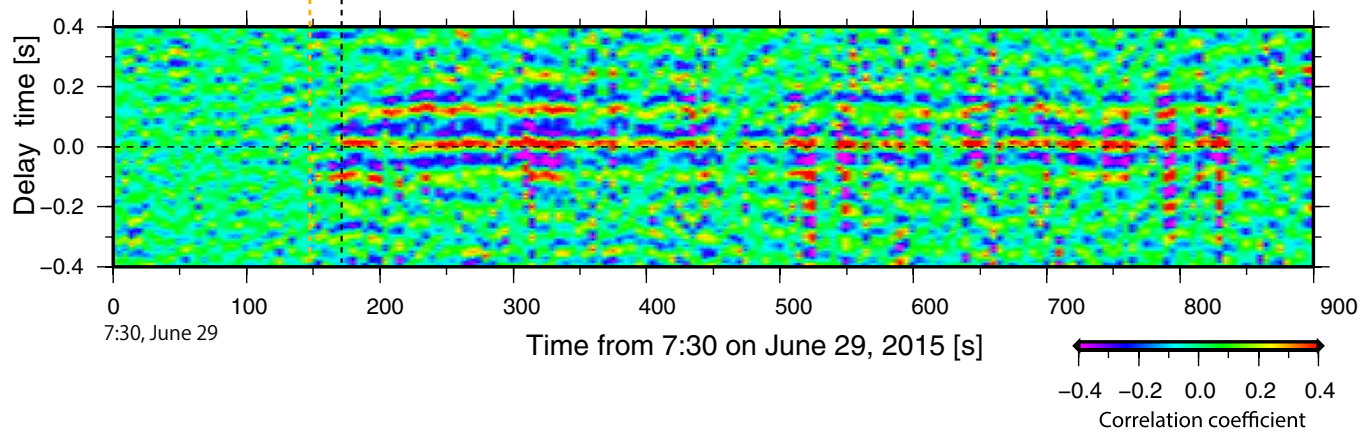

Fig. 3 Seismic and microphone records at the OWD station during the rapid tilt change. The raw and band-passed signals of $\mathbf{a}$ a seismometer (vertical component) and $\mathbf{b}$ a microphone. $\mathbf{c}$ RMS amplitude during a 1-s moving window of the band-passed signals. $\mathbf{d}$ Time sequence of the tiltmeters at the KOM and KZR stations. eThe microphone-seismometer correlation function with a 5-s moving window. The yellow and black broken lines show the onset of the seismic RMS amplitude and the rapid tilt change, respectively

the spatial distribution of the volumetric strain changes at the surface of the Owakudani region (at an elevation of $1000 \mathrm{~m}$ ) using the crack model of Honda et al. (2017). The final static strain changes because of the crack opening were calculated using the formula of Okada (1992). This result indicates that a positive (dilatational) volumetric strain change of more than $25 \mu$ acted on the area around the vents at the end of the rapid tilt change. This value of the strain change corresponds to a depressurization of approximately $0.16 \mathrm{MPa}$, which is 1.6 times greater than the atmospheric pressure near the surface if we set the rigidity to $3.9 \mathrm{GPa}$ as calculated assuming an $S$-wave velocity of $1.4 \mathrm{~km} / \mathrm{s}$ in the surface layer of the Hakone caldera (Oda 2008) and a rock density of $2.0 \mathrm{~g} /$ $\mathrm{cm}^{3}$. If we use the other crack model estimated using the InSAR data (Doke et al. 2017) to calculate the strain change, a large volumetric strain area of more than $25 \mu \mathrm{m}$ is also produced around the vents (Additional file 4: Figure A4). The detailed distribution of the volumetric strain changes is expected to change when considering the differences between the fault models, the heterogeneity of the displacement, and the effect of topography. However, it is certain that dilatational volumetric strain changes comparable to an order of magnitude of $10 \mu \mathrm{m}$ acted on a broad area in the Owakudani geothermal region because of the opening of the crack. It is reasonable to believe that groundwater near the boiling temperature preexisted beneath the Owakudani geothermal region prior to the eruption because fumarolic activity was previously observed. Even though a dynamic time sequence of strain 

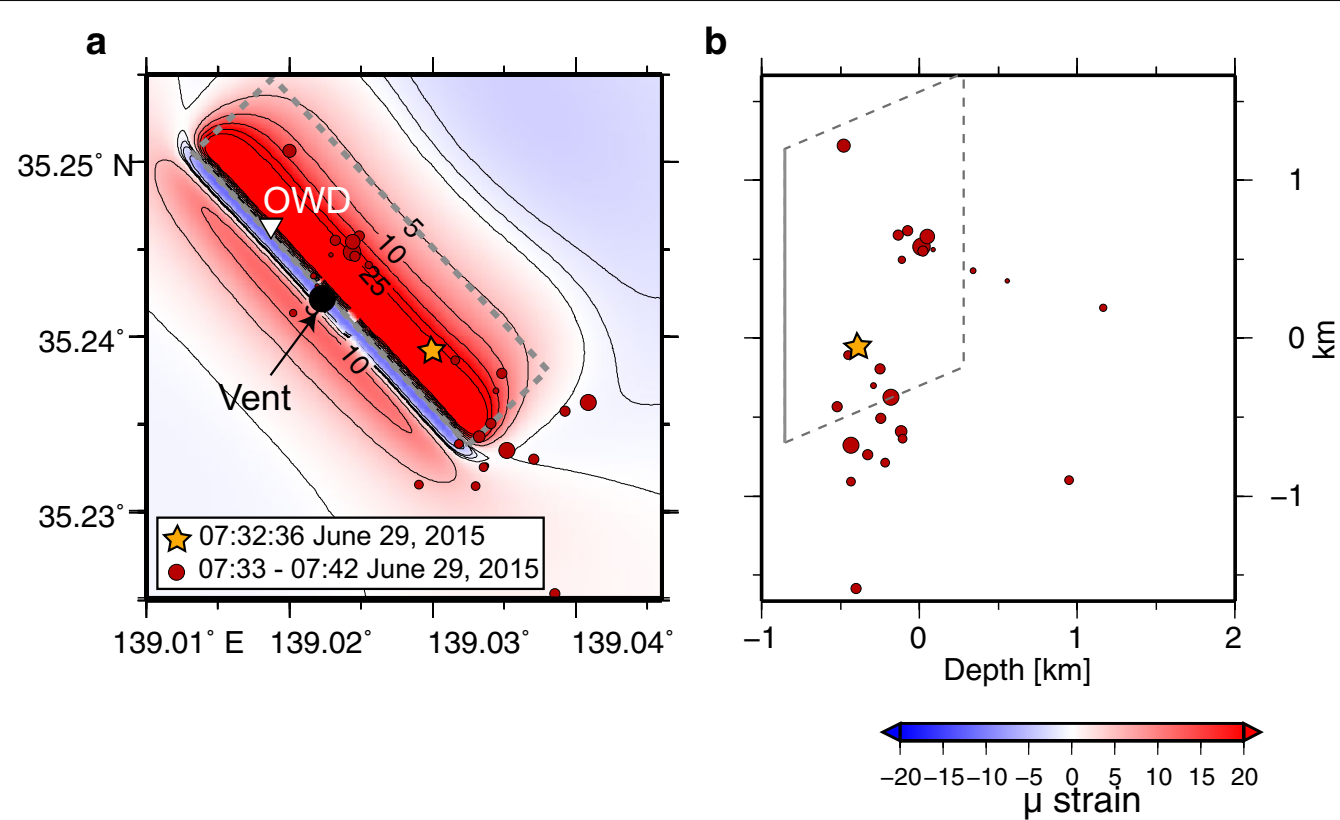

Fig. 4 Volumetric strain changes resulting from the crack opening. a Map view of the volumetric strain change at an elevation of $1000 \mathrm{~m}$ around the Owakudani region. A star and the red circles show the first and subsequent VT events, respectively, during the 10 min after the onset of the rapid tilt change, as estimated by Yukutake et al. (2017). b Depth distribution of the VT events along a N-S section

change was not considered here, the infrasonic wave coincident with the rapid tilt changes may be attributed to the emission of vapor caused by groundwater boiling due to depressurization resulting from the strain transfer (Fig. 5).

Figure 3 indicates that the increase in the seismic amplitude occurred approximately $20 \mathrm{~s}$ before the occurrence of the infrasonic wave. The VT earthquakes that occurred near the onset of the rapid tilt changes were distributed near an elevation of $0 \mathrm{~km}$ (approximately sea level) beneath Owakudani (Fig. 4). The result suggests that the pressure of the hydrothermal fluid at depth initially increased, thus triggering the VT earthquakes at depth and subsequently opening the shallow crack (Fig. 5).

On the other hand, Yukutake et al. (2017) reported discrete impulsive infrasonic waves coincident with the increase in the volcanic tremor amplitude. The corresponding signal was detected as the correlation patterns at 06:57 and 10:32 on June 30 and from 04:05 to 06:00 on July 01 (Fig. 2f). The last period contains the most pronounced impulsive signal activity. During this period, the largest vent (15-1 in Fig. 1b) formed (Mannen et al. 2015). Yukutake et al. (2017) suggested that the impulsive infrasonic waves were generated by the bursting of a gas slug at the surface vent during groundwater boiling, which was likely caused by heat transfer from the open crack.

\section{Conclusions}

We detected infrasound signals associated with eruptive activity in the Owakudani geothermal region during the opening of a shallow crack using a cross-correlation method between infrasound and vertical ground velocity. The correlation pattern showing the infrasound signal associated with the volcanic source occurred nearly simultaneously as the rapid tilt change related to the opening of a crack beneath the Owakudani geothermal region. Given that the upper end of the open crack is approximately $150 \mathrm{~m}$ beneath the surface, the direct emission of highly pressurized hydrothermal fluid from the open crack is not plausible because of the hydraulic diffusivity in this region. The instantaneous response of the infrasonic wave may reflect rapid vaporization of groundwater beneath Owakudani caused by the strain transfer resulting from the crack opening. We also detected a correlation pattern corresponding to discrete impulsive infrasound signals at 06:57 and 10:32 on June 30 and from 04:05 to 06:00 on July 01 that may be related to the behavior of a gas slug at the surface vent. The most pronounced impulsive infrasound activity was detected approximately 2 days after the rapid tilt change, during which the largest vent formed. These results suggest that the sudden emission of vapor occurred simultaneously with the inflation of the shallow pressure source, whereas the eruptive burst events accompanied by the largest vent formation were delayed for 2 days. We demonstrated that the infrasonic wave during the phreatic eruption, even with a small amplitude on the order of less than $1 \mathrm{~Pa}$, could be distinguished from wind and seismic noise using the correlation method. Furthermore, this study 
a $7: 32: 30$ June 29,2015

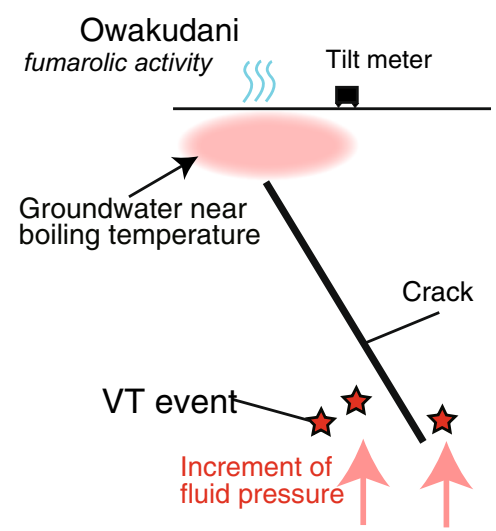

b $7: 32: 50$ June 29,2015

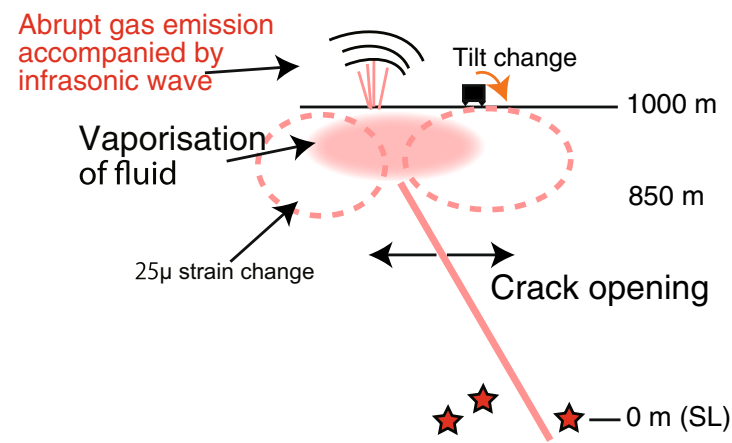

Fig. 5 Schematic illustration of the occurrence of an infrasonic wave accompanied by the crack opening. a The abrupt increase in the seismic amplitude occurred at 07:32:30 on June 29, 2015. b The infrasonic wave was generated coincident with the crack opening after 07:32:50 resulting from the strain transfer due to the open crack

showed that the correlation method is a powerful tool for monitoring surface phenomena at vents when only one microphone is available.

\section{Additional files}

Additional file 1. Photographs near the vents (Owakudani) taken using a time-lapse camera before and during the rapid tilt change.

Additional file 2. Calibration test for the microphone at the OWD station.

Additional file 3. Shift in the peaks and node of the seismic-infrasonic correlation resulting from background seismic oscillation.

Additional file 4. Strain changes using the open crack model estimated by InSAR data.

\section{Authors' contributions}

YY analyzed the infrasound data and wrote the manuscript. MI supported the data processing and assisted with the interpretation. $\mathrm{RH}$ analyzed the tilt record. All authors read and approved the final manuscript.

\section{Author details}

${ }^{1}$ Hot Springs Research Institute of Kanagawa Prefectural Government, 586 Iriuda, Odawara, Kanagawa, Japan. ${ }^{2}$ Earthquake Research Institute, The University of Tokyo, 1-1-1 Yayoi, Bunkyo-ku, Tokyo, Japan.

\section{Acknowledgements}

We used data from a microphone installed by the Japan Meteorological Agency. Dr. Kazutaka Mannen provided photographs taken during the eruption. We are thankful to the two anonymous reviewers and Editor Haruhisa Nakamich who helped in significantly improving the manuscript.

\section{Competing interests}

The authors declare that they have no competing interests.

\section{Availability of data and materials}

The data that support the findings in this study are available from the corresponding author on request.

Ethics approval and consent to participate Not applicable.

\section{Funding}

The present study was supported by a Grant-in-Aid for Young Scientists (B) (JSPS KAKENHI No. 15K17755). This study was also supported by the Earthquake Research Institute at the University of Tokyo cooperative research program (2016-B-03).

\section{Publisher's Note}

Springer Nature remains neutral with regard to jurisdictional claims in published maps and institutional affiliations.

Received: 27 December 2017 Accepted: 21 March 2018

Published online: 28 March 2018

\section{References}

Aoyama H, Oshima H (2015) Precursory tilt changes of small phreatic eruptions of Meakan-dake volcano, Hokkaido, Japan, in November 2008. Earth Planets Space 67(1):119. https://doi.org/10.1186/s40623-015-0289-9

Barberi F, Bertagnini A, Landi P, Principe C (1992) A review on phreatic eruptions and their precursors. JVolcanol Geotherm Res 52(4):231-246. https://doi.org/10.1016/0377-0273(92)90046-G

Ben-Menahem A, Singh SJ (1981) Seismic waves and sources, 2nd edn. Springer, Dover

Doke R, Harada M, Mannen K, Itadera K, Takenaka J (2017) Hydrothermal system in the shallow part of Hakone Volcano inferred from surface displacements of the 2015 phreatic eruption. In: Abstracts of the Volcanological Society of Japan 2017 Fall Meeting (in Japanese): P056

Garcés M, Harris A, Hetzer C, Johnson J, Rowland S, Marchetti E, Okubo P (2003) Infrasonic tremor observed at Kīlauea Volcano, Hawai'i. Geophys Res Lett 30(20):2023. https://doi.org/10.1029/2003GL018038

Honda R, Yukutake Y, Itadera K, Morita Y, Sakai S (2017) Reanalysis of tilt changes during volcanic activity on Hakone volcano in 2015. In: Abstracts of the Volcanological Society of Japan 2017 fall meeting, Abstr no: P054 (in Japanese)

Ichihara M, Takeo M, Yokoo A, Oikawa J, Ohminato T (2012) Monitoring volcanic activity using correlation patterns between infrasound and ground motion. Geophys Res Lett 39(4):L04304. https://doi. org/10.1029/2011GL050542

Iguchi M, Nakamichi H, Tameguri T, Yamamoto K, Mori T, Ohminato T, Saito E (2017) Contribution of monitoring data to decision making for evacuation from the 2014 and 2015 eruptions of Kuchinoerabujima Volcano. J Nat Disaster Sci 38:31-47 
Kokubo K (2013) Response of tiltmeters to volcanic crustal deformation models that include short period components. Q J Seismol 77:1-14 (in Japanese with English abstract)

Mannen K, Doke R, Harada M, Honda R, Itadera K, Kikugawa G, Yukutake Y, Takenaka J (2015) Chronology of the 2015 eruption of Hakone volcano, Japan. In: Abstracts of the Volcanological Society of Japan 2015 Fall Meeting (in Japanese): A3-12

Matoza RS, Fee D (2014) Infrasonic component of volcano-seismic eruption tremor. Geophys Res Lett 41(6):1964-1970. https://doi. org/10.1002/2014GL059301

Nagai M, Miwa T, Mannen K, Ishizuka Y, Yamasaki S, Furukawa R, Yoshimoto M, Tsunematsu K, Uchiyama T, Baba A, Suzuki Y (2015) The craters of the 2015 eruption of Hakone volcano, Japan. In: Abstracts of the Volcanological Society of Japan 2015 Fall Meeting (in Japanese): A3-14

Oda Y (2008) Seismic velocity structure beneath Hakone volcano. Res Rep Kanagawa Prefect Mus Nat Hist 13:171-186 (in Japanese with English abstract)

Okada Y (1992) Internal deformation because of shear and tensile faults in a half-space. Bull Seismol Soc Am 82(2):1018-1040

Ripepe M, Marchetti E (2002) Array tracking of infrasonic sources at Stromboli volcano. Geophys Res Lett 29(22):2076. https://doi. org/10.1029/2002GL015452
Takagi A, Onizawa S (2016) Shallow pressure sources associated with the 2007 and 2014 phreatic eruptions of Mt. Ontake, Japan. Earth Planets Space 68(1):135. https://doi.org/10.1186/s40623-016-0515-0

Takarada S, Oikawa T, Furukawa R, Hoshizumi H, Ji Itoh, Geshi N, Miyagi I (2016) Estimation of total discharged mass from the phreatic eruption of Ontake Volcano, central Japan, on September 27, 2014. Earth Planets Space 68(1):138. https://doi.org/10.1186/s40623-016-0511-4

Yokoo A, Ichihara M (2012) Cross correlation analysis of infrasound and seismic signals at Aso volcano (in Japanese). Chikyu Month Symp 34:2-15

Yukutake Y, Ito H, Honda R, Harada M, Tanada T, Yoshida A (2011) Fluidinduced swarm earthquake sequence revealed by precisely determined hypocenters and focal mechanisms in the 2009 activity at Hakone volcano, Japan. J Geophys Res 116(B4):B04308. https://doi. org/10.1029/2010jb008036

Yukutake Y, Honda R, Harada M, Doke R, Saito T, Ueno T, Si Sakai, Morita Y (2017) Analyzing the continuous volcanic tremors detected during the 2015 phreatic eruption of the Hakone volcano. Earth Planets Space 69(1):164. https://doi.org/10.1186/s40623-017-0751-y

\section{Submit your manuscript to a SpringerOpen ${ }^{\odot}$ journal and benefit from:}

- Convenient online submission

- Rigorous peer review

- Open access: articles freely available online

- High visibility within the field

- Retaining the copyright to your article

Submit your next manuscript at $\boldsymbol{\nabla}$ springeropen.com 